\title{
A METHODOLOGY TO SUPPORT DECISIONS TOWARDS ECONOMIC AND ENVIRONMENTAL SUSTAINABILITY IN PUBLIC CONTEXTS: APPLICATION TO HAND-DRYING OPTIONS
}

\author{
MARCO SCHIAVON ${ }^{1}$, MARCO RAGAZZI ${ }^{1}$, GRAZIANO COLLER ${ }^{2}$, NAVARRO FERRONATO ${ }^{3}$, \\ VINCENZO TORRETTA ${ }^{3} \&$ ELENA CRISTINA RADA $^{3}$ \\ ${ }^{1}$ Department of Civil, Environmental and Mechanical Engineering, University of Trento, Italy \\ ${ }^{2}$ Department of Economics and Management, University of Trento, Italy \\ ${ }^{3}$ Department of Theoretical and Applied Sciences, University of Insubria, Italy
}

\begin{abstract}
Different hand-drying methods entail different costs and impacts on humans and the environment. This paper presents a methodology to facilitate the decision on the convenience of installing electrical hand driers in place of the conventional toilet paper towels in the restrooms of public places. Specifically, a procedure including both economic and environmental aspects is proposed and the Monte Carlo method is employed to account for the several uncertainties of all the variables involved. From the economic point of view, the number of daily usages of restrooms results as the key variable determining if one option is preferable to the other. From the environmental point of view, the carbon footprint was calculated for four scenarios considering two options for the electric energy grid mix and two options for waste treatment. The comparison between the four scenarios revealed that hand driers may be preferable to paper towels when the waste treatment alternative is landfilling. The results are more uncertain when the waste treatment option is incineration. The integration of economic and environmental aspects reveals as a useful strategy to fully assess the convenience of choosing one option rather than another, without limiting the decision to only one aspect. Additional information on processes and logistics are anyway necessary to reduce the uncertainties of the results.

Keywords: paper towels, hand driers, Monte Carlo method, carbon footprint, energy consumption, waste management, greenhouse gases, road transport, incineration, landfilling.
\end{abstract}

\section{INTRODUCTION}

Buildings are important final consumers of energy and, consequently, high direct and indirect contributors to the emissions of greenhouse gases (GHGs) into the atmosphere [1]. Depending on their contexts, the energy demand by buildings is about $25-45 \%$ the worldwide energy demand [2], [3]. In public buildings, there is also a general growing concern towards public hygiene, which should be pursued with sustainable strategies to limit both the costs for the society and the impacts of different alternatives on the environment. Besides hand washing, hand drying is an important step in public hygiene, because of the demonstrated higher potentials for carrying microbes (and, thus, infections) on wet hands, in comparison with dry hands [4].

Different hand-drying methods exist: paper towels, cotton rolls and electric hand-driers. The last are warm- or hot-air hand driers (which generate a low-speed warm/hot airflow), high-speed hand driers (which dry users' hands by a jet of unheated air) and the more recent airblade-type hand driers (whose effect is given by a thin layer of unheated air exiting at a higher speed than jet-air hand driers). Different hand-drying methods entail different impacts on humans and the environment. Compared to paper roll/towels, hand driers generally show higher impacts in terms of dispersion of airborne bacteria. In a dated study, Matthews and Newsome [5] found no significant differences between the concentrations of bacteria aerosols in proximity of a hot-hair hand drier and a paper towel dispenser. In a more recent 
study, paper towels showed a 6-fold lower impact than warm-air hand driers and a 27-fold lower impact than airblade-type hand driers [6]. However, generally lower impacts are expected from a Life Cycle Assessment (LCA) perspective. In a research carried out in 2011, the LCA procedure was applied to evaluate the overall impacts of several hand-drying methods such as virgin paper towels, $100 \%$ recycled paper towels, cotton-roll towels, standard electrical hand driers, high-speed hand driers and the airblade-type hand driers [7]. The results of the LCA of the different hand-drying methods showed that the airblade-type hand driers are expected to generate the lowest environmental impacts, followed by highspeed hand driers, cotton-roll towels, $100 \%$ recycled paper towels, standard electrical hand driers and virgin paper towels [7].

In view of such results, the present paper intends to present a methodology facilitating the decision on the convenience to install electrical hand driers in place of the conventional toilet paper towels in the restrooms of public places, based on a quantitative economic criterion and on environmental aspects. This work moves from the need for implementing sustainable actions in Italian universities that are being promoted by a recent association between Italian academic institutions [8]. The target of this study is a medium-size university located in northern Italy. At present, with a few exceptions, the large majority of restrooms in the different departments of the university are equipped with traditional paper towels for hand drying. Considered the previous results on the overall sustainability of different hand-drying methods, this paper presents a comparison between the present situation (use of paper towels) and an alternative one, based on the installation of an airblade-type hand drier in restrooms responding to a specific criterion. Indeed, installing airblade-type hand driers in all restrooms would not be a convenient solution from the economic point of view, since such hand driers present a considerable fixed cost, quantified as approximately $1,000 €$. Thus, it is necessary to formulate a decision criterion to evaluate which restrooms are suitable for having paper towels replaced with electric hand driers. In addition, considerations will be expressed on the comparison between the carbon footprint generated by the present situation and the one expected in the alternative scenario. To the authors' knowledge, this is the first proposal for a methodology supporting decision processes in this field.

\section{MATERIALS AND METHODS}

\subsection{Definition of the decision criterion}

The installation of an electrical hand drier implies a fixed cost related to the purchase of the machine and variable costs related to the electric energy consumption associated with its usage. Paper towels are characterised by their purchase cost and by costs related to the collection, transportation and management of the used towels, which are regarded as residual waste. In the case of the University of Trento, the local municipality applies a waste management fare that is composed by a fixed cost and a variable cost that depends on the volume of waste generated. However, in the case of large production of waste, this cost can be approximated to the variable cost that is about $0.05 € / \mathrm{L}$. Due the presence of one scenario characterised by fixed and variable costs (airblade-type hand drier) and another scenario which entails only variable costs (paper towels), the economical convenience of installing an airblade-type hand drier in a restroom in place of paper towels can be evaluated on the basis of the average number of daily usages of the restroom by users. In other words, the target is to estimate the minimum number of daily usages above which installing an airblade-type hand drier allows for lower costs compared to the use of paper towels like in the current situation. The minimum number of daily usages is the number of daily usages that makes the 
annual costs of using paper towels $\left(C_{p}\right)$ equal to the annual costs of an airblade-type hand $\operatorname{drier}\left(C_{h d}\right) . C_{p}$ can be expressed as:

$$
C_{p}=N \cdot n_{d, w e e k} \cdot n_{w e e k, y} \cdot n_{p, u}\left(C_{p, p}+C_{p, w d}\right),
$$

where:

- $\quad N$ is the average number of daily usage of a restroom [-];

- $n_{d, \text { week }}$ is the number of working days in a week $[\mathrm{d} /$ week];

- $n_{\text {week,y }}$ is the number of working weeks in a year [weeks/y];

- $\quad n_{p, u}$ is the number of paper towels used by each user [1/user];

- $C_{p, p}$ is the cost of each paper towel [€/towel];

- $C_{p, w d}$ is the cost for waste disposal of each paper towel [€/towel].

$C_{h d}$ can be formulated as:

$$
C_{h d}=\frac{C_{h d, f}}{T}+N \cdot n_{d, w e e k} \cdot n_{w e e k, y} \cdot t_{h d, u} \cdot C_{e} \frac{P}{1000 \frac{W}{k W} \cdot 3600 \frac{s}{h}}
$$

where:

- $\quad C_{h d, f}$ is the initial (fixed) cost for the purchase of an airblade-type hand drier [€];

- $\quad T$ is the lifetime of an airblade-type hand drier $[y]$;

- $\quad P$ is the power consumption of an airblade-type hand drier [W];

- $\quad t_{h d, u}$ is the time of usage of a hand drier by a user [s/user];

- $C_{e}$ is the average cost of electric energy [€/kWh].

By equalling (1) with (2), the number of daily usages of a restroom that would result in an economic benefit if paper towels were replaced with an airblade-type hand drier is:

$$
N=\frac{C_{h d, f}}{T \cdot n_{d, \text { week }} \cdot n_{\text {week }, y}\left[n_{p, u}\left(C_{p, p}+C_{p, w d}\right)-\frac{P \cdot t_{h d, u} \cdot C_{e}}{1000 \frac{W}{k W} \cdot 3600 \frac{s}{h}}\right]} .
$$

$C_{p, p}, C_{h d, f}$ and $P$ can be obtained by the suppliers, while $n_{d, w e e k}$ and $n_{\text {week,y }}$ can be assumed as equal to $5 \mathrm{~d} /$ week and 50 weeks/y, considered that a university can be officially closed two weeks a year. The quantification of $C_{p, w d}, T, t_{h d, u}$ and $n_{p, u}$ is much more difficult, due to the high degree of uncertainty that should be considered for their estimation. Concerning $C_{p, w d}$, since the volume occupied by one package of 150 new paper towels is about $1.8 \mathrm{~L}$, each new paper towel would occupy a volume of about $0.012 \mathrm{~L}$. It is reasonable to assume that the volume occupied by a wet paper towel may double this value. Concerning $T$, the only useful information is the lasting of the guarantee issued by one supplier, which is 5 years. Regarding $t_{h d, u}$, it is reasonable to consider a mean value between 10 and $15 \mathrm{~s}$. Finally, a mean value between 2 and 3 paper towels was assumed for $n_{p, u}$.

To account for the variability of the previous variables, a statistical approach was used, based on the Monte Carlo method [9]. Specifically, each variable was associated to a Gaussian probability function, characterised by a specific mean value $(\mu)$ and a standard deviation $(\sigma)$. For each variable, a sample of 10,000 values was obtained, complying with the associated probability density function. Table 1 reports the values of $\mu$ and $\sigma$ given to each variable characterised by uncertainty and the values of the parameters whose definition is considered as certain. N was then calculated by applying (3) to 10,000 combinations of $C_{p, w d}$, $T, t_{h d, u}$ and $n_{p, u}$.

Eqn (3) can also be rearranged as follows: 


$$
N=\frac{C_{h d, f}}{T \cdot n_{d, w e e k} \cdot n_{w e e k, y}} \cdot \frac{1}{n_{p, u}\left(C_{p, p}+C_{p, w d}\right)-\frac{P \cdot t h d, u}{1000 \frac{W}{k W} \cdot 3600 \frac{s}{h}}},
$$

where:

- $\quad C_{h d, f} /\left(T \cdot n_{d, w e e k} \cdot n_{w e e k, y}\right)$ is the daily fixed cost for the purchase of an airbladetype hand drier;

- $n_{p, u}\left(C_{p, p}+C_{p, w d}\right)$ is the variable cost of a single usage of the restroom equipped with paper towels $\left(C_{p, v}\right)$;

- $\left(P \cdot t_{h d, u} \cdot C_{e}\right) /\left(1000 \frac{W}{k W} \cdot 3600 \frac{s}{h}\right)$ is the variable cost of a single usage of the restroom equipped with an airblade-type hand drier $\left(C_{h d, v}\right)$;

The value of $N$ is highly affected by these values. The difference between variable costs of paper towels and of the airblade-type hand drier $C_{p, v}-C_{h d, v}$ gives the cost reduction entailed by a single use of an air drier. Notice that with $C_{p, v}<C_{h d, v}$ it is never convenient to install the airblade-type hand drier. However, since $V_{\text {air }}$ is the energy consumption of a single usage of the air hand drier (few seconds with an hourly cost of few cents) this is an unlikely situation. With $C_{p, v}>C_{h d, v}$, which is the most likely hypothesis, the higher the difference $C_{p, v}-C_{h d, v}$, the lower is $N$.

Even more important in determining $N$ is the daily fixed cost for purchase of the airbladetype hand drier. Given $C_{h d, f}$ and keeping all the rest equal, the daily fixed cost of the airbladetype hand drier heavily depends on the estimated life of the equipment, and doubling the equipment estimated life (e.g. from 5 to 10 years) halves $N$.

\subsection{Estimation of the carbon footprint}

The current use of paper towels in restrooms induces emissions of GHGs by the transportation of the product from the production facility to the final user (a university in this case) and by the transportation of waste paper towels from the user to the final waste management facility. GHG emissions from the transportation sector consists in the emissions

Table 1: $\quad \mu$ and $\sigma$ of the probability density functions assumed for $\mathrm{Cp}, \mathrm{wd}, \mathrm{T}$, thd, $\mathrm{u}$ and $\mathrm{np}, \mathrm{u}$, respective minimum and maximum values obtained through the Monte Carlo simulation and values assumed for the remaining parameters.

\begin{tabular}{|c|c|c|c|c|c|}
\hline $\begin{array}{l}\text { Variables calculated via } \\
\text { Monte Carlo simulation }\end{array}$ & $\mu$ & $\sigma$ & $\min$ & $\max$ & unit \\
\hline$C_{p, w d}$ & 0.0015 & 0.0002 & 0.0008 & 0.0023 & $€ /$ towel \\
\hline$n_{p, u}$ & 2.5 & 0.5 & 0.6 & 4.2 & $1 /$ user \\
\hline$T$ & 7.5 & 0.6 & 5.2 & 9.6 & $\mathrm{y}$ \\
\hline$t_{h d, u}$ & 12.5 & 1.0 & 9.0 & 17.9 & $\mathrm{~s}$ \\
\hline Parameters assumed as certain & \multicolumn{4}{|c|}{ Reference value } & \\
\hline$C_{p, p}$ & \multicolumn{4}{|c|}{0.005} & $€ /$ towel \\
\hline$C_{h d, f}$ & \multicolumn{4}{|c|}{1,000} & $€$ \\
\hline$P$ & \multicolumn{4}{|c|}{1600} & W \\
\hline$n_{d, \text { week }}$ & \multicolumn{4}{|c|}{5} & $\mathrm{~d} /$ week \\
\hline$n_{\text {week }, y}$ & \multicolumn{4}{|c|}{50} & weeks/y \\
\hline
\end{tabular}


of carbon dioxide $\left(\mathrm{CO}_{2}\right)$ both from the fuel consumption of vehicles, from the combustion of lube oil and, in the case of the latest heavy-duty vehicles, from the catalysis of urea, which is used as an additive to reduce nitrogen oxides in diesel exhaust gases [10]. In addition, minor emissions of nitrous oxide $\left(\mathrm{N}_{2} \mathrm{O}\right)$ and methane $\left(\mathrm{CH}_{4}\right)$ occur, but such gases are characterised by high global warming potentials. They were respectively assumed as equal to 282 and 32 (i.e., as equal to the mean values of the respective ranges proposed by the Intergovernmental Panel on Climate Change, which are 265-298 and 28-36 on a 100-year time horizon [11]). To estimate GHG emissions from the transportation of paper towels, it is assumed that both the carriage of waste is carried out by heavy-duty vehicles (HDVs) with a maximum gross weight of $26 \mathrm{t}$ and a tare of $10 \mathrm{t}$, in accordance with a previous work [12]. HDVs were assumed to belong to the Euro VI emissive standard [13]. Depending on the pollutant and emission mechanism, emission factors for $\mathrm{CO}_{2}, \mathrm{~N}_{2} \mathrm{O}$ and $\mathrm{CH}_{4}$ from European vehicles can be calculated or are directly proposed by a consolidated methodology developed by the European Environment Agency [10]. Specifically, According to this methodology, $\mathrm{CO}_{2}$ emissions can be estimated as functions of the fuel consumption that depend on the mechanism of $\mathrm{CO}_{2}$ generation. The $\mathrm{CO}_{2}$ emission factor of a generic $i$-type vehicle related to fuel combustion is defined as:

$$
E F_{C O_{2}, F C_{i}}=44.011 \cdot \frac{F C_{i}}{12.011+1.008 \cdot r_{H: C, j}+16 \cdot r_{O}: C, j},
$$

where $F C_{i}$ is the fuel consumption of the $i$-type vehicle, $r_{H: C, j}$ and $r_{O: C, j}$ are respectively the hydrogen-to-carbon and oxygen-to- carbon ratios of the $j$-type fuel. In the case of gasoil, $r_{H: C}$ and $r_{O: C}$ are assumed as 1.86 and 0 , respectively. In the case of an HDV, FC is assumed as $240 \mathrm{~g} / \mathrm{km}$ [10]. Eqn (4) applies also to the calculation of the $\mathrm{CO}_{2}$ emissions from lube oil combustion, with the only difference that $F C_{i}$ must be replaced by the oil consumption of the i-type vehicle $\left(O C_{i}\right)$ and that $r_{H: C}$ and $r_{O: C}$ are respectively 2.06 and 0 in this case. $O C$, in the case of an $\mathrm{HDV}$, is $0.156 \mathrm{~g} / \mathrm{km}$. $\mathrm{CO}_{2}$ emissions from urea catalysis, in the present case, can be calculated as [10]:

$$
E F_{\mathrm{CO}_{2}, U C_{i}}=0.0078 \cdot F C_{i} .
$$

The $\mathrm{N}_{2} \mathrm{O}$ emission factor for the considered HDV is $0.032 \mathrm{~g} / \mathrm{km}$, while the $\mathrm{CH}_{4}$ emission factor for the same HDV is $0.070 \mathrm{~g} / \mathrm{km}$ assuming that the transport occurs on highways [10]. The $\mathrm{N}_{2} \mathrm{O}$ and $\mathrm{CH}_{4}$ emission factors must be multiplied by their respective global warming potentials to give $\mathrm{CO}_{2}$-equivalent $\left(\mathrm{CO}_{2 \mathrm{eq}}\right)$ emission factors. By summing up all contributions, the $\mathrm{CO}_{2 \text { eq }}$ emission factor becomes $775 \mathrm{~g} / \mathrm{km}$. The total annual $\mathrm{CO}_{2 \mathrm{eq}}$ emissions essentially depend on the total travelled distance for waste carriage and on the number of travels, which can be parametrised on the basis of the annual amount of used paper towels, of the mass of each waste towel and of the maximum capacity of the HDV (16 t). Reasonably, each waste towel was assumed to be completely wet, since the transportation of waste is likely to occur before waste towels have dried. Thus, the density of waste paper towels was assumed as equal to the water density $(1 \mathrm{~kg} / \mathrm{L})$. Given the assumption made on the volume of waste paper towels, the mass of each waste towel was considered as equal to $24 \mathrm{~g}$.

Additional contributions are related to the final waste treatment. In the case that waste paper towels are sent to incineration, the biogenic origin of the cellulose of paper towels [14] would not generate net $\mathrm{CO}_{2}$ emissions. In the case waste paper towels are sent to a municipal landfill, the biodegradation of cellulose contributes to the formation of biogas, whose volume fraction that is normally considered as intercepted by the biogas capture system is limited to about $75 \%$ [15]. According to a recent work [16], the $\mathrm{CH}_{4}$ yield of cellulose during anaerobic digestion can be assumed as $0.35 \mathrm{Nm}^{3} / \mathrm{kg}$ of the volatile solid content, which was estimated 
as equal to $97.3 \%$. Considered the molecular masses of $\mathrm{CH}_{4}$, the global warming potential of $\mathrm{CH}_{4}$ and the interception rate of the biogas capture system, $1 \mathrm{~kg}$ of waste paper towels sent to a landfill can lead to a net $\mathrm{CO}_{2 \mathrm{eq}}$ emission of $2.5 \mathrm{~kg}$. To estimate the $\mathrm{GHG}$ emissions related to the landfilling of paper towels, the mass of one paper towel was measured with a laboratory scale (AS120, OHAUS Corp., USA) and resulted as $1.70 \mathrm{~g}$.

The above-reported considerations allow estimating the $\mathrm{CO}_{2 \mathrm{eq}}$ emissions related to the use of toilet paper towels in different situations. Specifically, it is possible to express the total $\mathrm{CO}_{2 \text { eq }}$ emissions as a function of the distance travelled by the HDVs transporting the waste towels and of the average number of daily usages of a restroom. The use of electrical hand driers entails $\mathrm{CO}_{2}$ emissions too in the case that electric energy is produced by the combustion of fossil fuels. To estimate the $\mathrm{CO}_{2}$ emissions from the use of hand driers, this paper considers the average grid mix of electric energy production by the different sources exploited in Italy (Table 2). By performing a weighted average of the emission factors based on the share of electric energy production by source, the average $\mathrm{CO}_{2}$ emission factor results as 333.2 $\mathrm{g} / \mathrm{kWh}$. According to an authoritative national institute [17], this value should be increased by about $0.5 \%$ to account for $\mathrm{CO}_{2 \text { eq }}$ emissions from the release of $\mathrm{N}_{2} \mathrm{O}$ and $\mathrm{CH}_{4}$ into the atmosphere, following fossil fuel combustion. Consequently, a $\mathrm{CO}_{2 \text { eq }}$ emission factor of $334.9 \mathrm{~g} / \mathrm{kWh}$ will be used to calculate the $\mathrm{CO}_{2 \mathrm{eq}}$ emissions induced by the use of an airbladetype hand drier ( $\left.E_{C O 2 e q, h d}\right)$ according to the following equation:

$$
E_{C O_{2 e q}, h d}=E F_{C O_{2 e q}, e l} \cdot \frac{P \cdot t_{h d, u}}{1000 \frac{W}{k W} \cdot 3600 \frac{s}{h}} \cdot N \cdot n_{d, w e e k} \cdot n_{w e e k, y}
$$

where $E F_{C O 2 e q, e l}$ is the average $\mathrm{CO}_{2 \text { eq }}$ emission factor from electric energy production. To provide practical examples of the different impacts expected by different waste treatment strategies and different percentages of electric energy produced by renewable sources (which do not contribute to $\mathrm{CO}_{2 \mathrm{eq}}$ emissions), the following scenarios are proposed:

- Case 1: electric energy is entirely produced by renewable sources;

- Case 2: electric energy is produced by the average mix of sources reported in Table 2 for the case study (i.e., by $32 \%$ renewable sources);

- Case 3: waste is sent to incineration for cogeneration of heat and power;

- Case 4: waste is sent to municipal landfills.

Cases 1 and 2 will be compared to Cases 3 and 4 in Section 3.2. However, due to the uncertainties in determining the travelled distance from the transportation of paper towels

Table 2: Average grid mix of electric energy among different sources in Italy and related $\mathrm{CO}_{2}$ emission factors [17].

\begin{tabular}{|c|c|c|c|c|}
\hline \multicolumn{2}{|c|}{ Energy source } & $\begin{array}{c}\text { Gross electric energy } \\
\text { production [TWh] }\end{array}$ & Share[-] & $\begin{array}{c}\mathrm{CO}_{2} \text { emission } \\
\text { factor [g/kWh] }\end{array}$ \\
\hline \multicolumn{2}{|c|}{ Hydroelectric } & 42.8 & $15 \%$ & 0 \\
\hline Thermoelectric & solid fuels & 43.2 & $15 \%$ & 899.9 \\
\hline & natural gas & 110.9 & $39 \%$ & 365 \\
\hline & derivative gas & 2.2 & $1 \%$ & 1624.8 \\
\hline & oil products & 13.4 & $5 \%$ & 564 \\
\hline & Other & 21.8 & $8 \%$ & 144 \\
\hline \multicolumn{2}{|c|}{ Geothermal } & 6.2 & $2 \%$ & 0 \\
\hline \multicolumn{2}{|c|}{ Wind and photovoltaic } & 40.5 & $14 \%$ & 0 \\
\hline
\end{tabular}


from the supplier to the final user, the calculation of the total GHG emissions from the use of paper towels will be limited to the transportation of waste towels and to the final waste treatment. In addition, this study considers relatively negligible the impacts related to the production processes of hand driers and paper towels.

\section{RESULTS AND DISCUSSION}

\subsection{Economic analysis}

The results of the Monte Carlo method showed that the minimum number of daily usages of restrooms that could lead to economic benefits if paper towels were replaced by an airbladetype hand drier is between 16 and 182. This apparently wide range must be interpreted with the frequency distribution reported in Fig. 1. Such distribution is characterised by a mean $N$ value of 36 and a mode of 32 . However, a precautionary approach should be considered, especially when the investors in renovations and technology improvements are public bodies. Such an approach would suggest that a reliable trigger to decide where airblade-type hand driers should be conveniently located could be a number of average daily usages $>90$. In a university, restrooms serving classrooms may respond to such characteristics.

Table 3 presents the estimated annual costs, calculated by applying (1) and (2), as a function of the number of daily usages, in the case of paper towels and of airblade-type hand driers. Costs are evaluated on the basis of minimum, maximum and most probable values of the single variable estimated through the Monte Carlo simulation.

In the present case study, 21 restrooms were identified as suitable to hosting an electric hand drier, thanks to the presence of wall sockets. Table 4 presents the estimated annual savings if one airblade-type hand drier was installed in each of the 21 restrooms. It is worth reminding that such values are only indicative, since they are influenced by the uncertainties on the variables listed in Table 1. In addition, the amortisation of the hand driers was not considered. Depending on the number of daily usages and considering the 21 restrooms, the minimum appreciable annual savings may start from a less than hundred Euro $(N=90)$ and

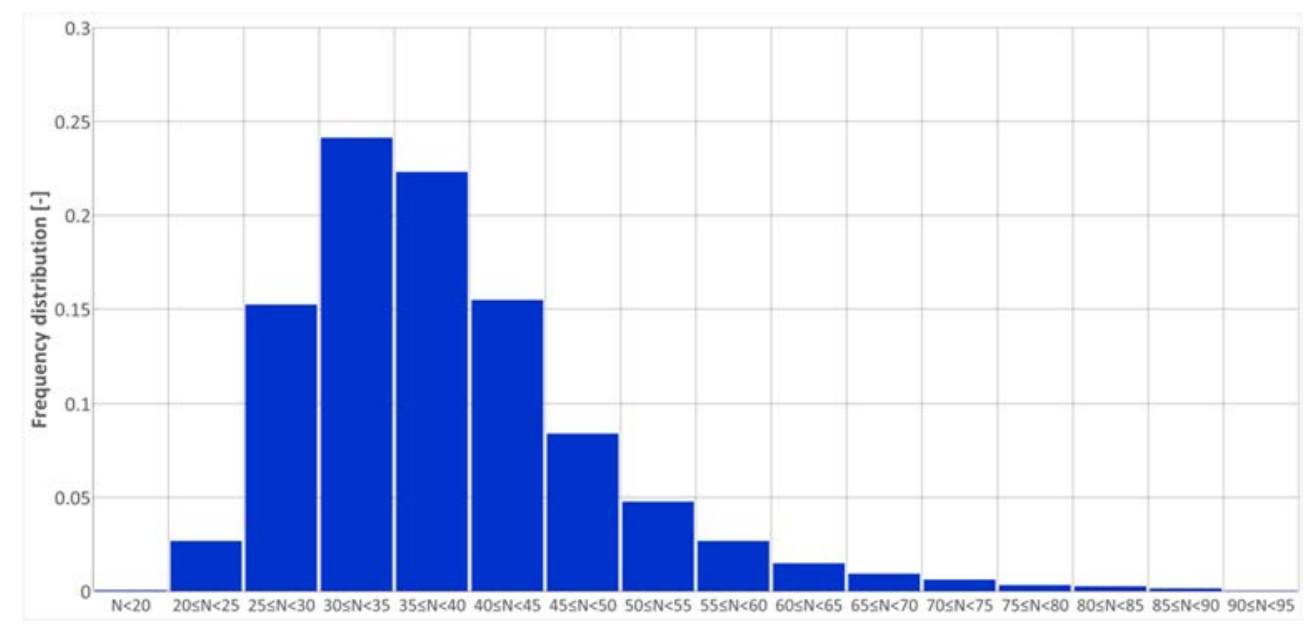

Figure 1: Frequency distribution of the minimum number of daily usages that would result in economic savings when installing an airblade-type hand drier in place of using paper towels. 
Table 3: Estimated annual costs, related to one restroom, as a function of the number of daily usages, in the case of paper towels and of airblade-type hand driers.

\begin{tabular}{|c|c|c|c|c|c|c|c|c|}
\hline & \multicolumn{4}{|c}{ Annual cost of paper towel [€] } & \multicolumn{3}{c|}{ Annual cost of a hand drier [€] } \\
\hline $\mathrm{N}$ & minimum & mean & modal & maximum & minimum & mean & modal & maximum \\
\hline 10 & 20.46 & 40.47 & 42.00 & 64.16 & 115.55 & 136.67 & 134.11 & 168.04 \\
\hline 20 & 40.93 & 80.94 & 84.01 & 128.31 & 118.16 & 139.85 & 137.19 & 171.79 \\
\hline 30 & 61.39 & 121.41 & 126.01 & 192.47 & 120.77 & 143.04 & 140.28 & 175.53 \\
\hline 40 & 81.86 & 161.88 & 168.01 & 256.63 & 123.38 & 146.23 & 143.37 & 179.27 \\
\hline 50 & 102.32 & 202.36 & 210.02 & 320.79 & 125.99 & 149.42 & 146.45 & 183.02 \\
\hline 60 & 122.79 & 242.83 & 252.02 & 384.94 & 128.60 & 152.61 & 149.54 & 186.76 \\
\hline 70 & 143.25 & 283.30 & 294.02 & 449.10 & 131.21 & 155.80 & 152.62 & 190.51 \\
\hline 80 & 163.72 & 323.77 & 336.03 & 513.26 & 133.82 & 158.99 & 155.71 & 194.25 \\
\hline 90 & 184.18 & 364.24 & 378.03 & 577.42 & 136.44 & 162.18 & 158.79 & 198.00 \\
\hline 100 & 204.65 & 404.71 & 420.03 & 641.57 & 139.05 & 165.36 & 161.88 & 201.74 \\
\hline 110 & 225.11 & 445.18 & 462.04 & 705.73 & 141.66 & 168.55 & 164.96 & 205.49 \\
\hline 120 & 245.58 & 485.65 & 504.04 & 769.89 & 144.27 & 171.74 & 168.05 & 209.23 \\
\hline 130 & 266.04 & 526.12 & 546.04 & 834.04 & 146.88 & 174.93 & 171.13 & 212.98 \\
\hline 140 & 286.51 & 566.60 & 588.05 & 898.20 & 149.49 & 178.12 & 174.22 & 216.72 \\
\hline 150 & 306.97 & 607.07 & 630.05 & 962.36 & 152.10 & 181.31 & 177.30 & 220.47 \\
\hline 160 & 327.43 & 647.54 & 672.05 & $1,026.52$ & 154.71 & 184.50 & 180.39 & 224.21 \\
\hline 170 & 347.90 & 688.01 & 714.06 & $1,090.67$ & 157.32 & 187.68 & 183.47 & 227.96 \\
\hline 180 & 368.36 & 728.48 & 756.06 & $1,154.83$ & 159.93 & 190.87 & 186.56 & 231.70 \\
\hline 190 & 388.83 & 768.95 & 798.06 & $1,218.99$ & 162.54 & 194.06 & 189.64 & 235.45 \\
\hline 200 & 409.29 & 809.42 & 840.07 & $1,283.14$ & 165.16 & 197.25 & 192.73 & 239.19 \\
\hline
\end{tabular}

Table 4: Estimated annual savings if one airblade-type hand drier was installed in each of the 21 restrooms considered in this study.

\begin{tabular}{|c|c|c|c|c|}
\hline & \multicolumn{4}{|c|}{ Estimated annual savings [€] } \\
\hline $\mathrm{N}$ & minimum & mean & modal & maximum \\
\hline 10 & $-3,099.09$ & $-2,020.10$ & $-1,934.23$ & $-1,079.21$ \\
\hline 20 & $-2,747.97$ & $-1,237.16$ & $-1,116.95$ & 213.26 \\
\hline 30 & $-2,396.85$ & -454.23 & -299.67 & $1,505.73$ \\
\hline 40 & $-2,045.74$ & 328.70 & 517.61 & $2,798.21$ \\
\hline 50 & $-1,694.62$ & $1,11.63$ & $1,334.90$ & $4,090.68$ \\
\hline 60 & $-1,343.50$ & $1,894.57$ & $2,152.18$ & $5,383.16$ \\
\hline 70 & -992.38 & $2,677.50$ & $2,969.46$ & $6,675.63$ \\
\hline 80 & -641.26 & $3,460.43$ & $3,786.74$ & $7,968.10$ \\
\hline 90 & -290.15 & $4,243.36$ & $4,604.02$ & $9,260.58$ \\
\hline 100 & 60.97 & $5,026.30$ & $5,421.30$ & $10,553.05$ \\
\hline 110 & 412.09 & $5,809.23$ & $6,238.58$ & $11,845.52$ \\
\hline 120 & 763.21 & $6,592.16$ & $7,055.87$ & $13,138.00$ \\
\hline 130 & $1,114.33$ & $7,375.09$ & $7,873.15$ & $14,430.47$ \\
\hline 140 & $1,465.45$ & $8,158.03$ & $8,690.43$ & $15,722.94$ \\
\hline 150 & $1,816.56$ & $8,940.96$ & $9,507.71$ & $17,015.42$ \\
\hline 160 & $2,167.68$ & $9,723.89$ & $10,324.99$ & $18,307.89$ \\
\hline 170 & $2,518.80$ & $10,506.83$ & $11,142.27$ & $19,600.36$ \\
\hline 180 & $2,869.92$ & $11,289.76$ & $11,959.55$ & $20,892.84$ \\
\hline 190 & $3,221.04$ & $12,072.69$ & $12,776.83$ & $22,185.31$ \\
\hline 200 & $3,572.15$ & $12,855.62$ & $13,594.12$ & $23,477.78$ \\
\hline
\end{tabular}


may reach $3,570 €(N=200)$. Higher savings could be reached with a higher number of usages. If considering the mean costs and the most probable costs, the estimated annual savings may start from 329-518 $€(N=40)$ and achieve $12,856-13,594 €(N=200)$. Conversely, the installation of airblade-type hand driers would be economically inconvenient in restrooms with a low number of daily usages, as in the case of restrooms for university staff and professors. Thus, in order to pursue guaranteed savings, the installation of airbladetype hand driers is recommended in averagely-to-highly frequented public places.

\subsection{Carbon footprint}

The $\mathrm{CO}_{2 \text { eq }}$ emissions related to the use of paper towels depend on two main variables: $N$ and the distance travelled by the HDVs transporting waste towels. Therefore, the difference between the emissions generated by the scenarios involving the use of hand driers and the scenarios that consider paper towels can be expressed as functions of those two variables.

Fig. 2 presents the results of the inter-comparison between Cases 1 and 3 (best-case situations), Cases 1 and 4 (mixed situations), Cases 2 and 3 (mixed situations), and Cases 2 and 4 (worst-case situations). The results are expressed as a function of $N$ and of the travelled distance and refer to the most probable values calculated by the Monte Carlo simulation. The results show that, if electric energy were produced by $100 \%$ renewable sources (Case 1), even in the best-case situation concerning the waste treatment of paper towels (incineration, Case 3 ), the use of paper towels rather than airblade-type hand driers entails GHG emissions $>0$ for any $N$ and travelled distance (Fig. 2(a)). GHG emissions would be much higher, compared to the best-case situation concerning hand driers (Case 1), if the final destination of waste paper towels were a landfill (Case 4), due to the generation of biogas and the consequent release of $\mathrm{CH}_{4}$ into the atmosphere (Fig. 2(b)). In this case, the expected increase in GHG emissions is insensitive to the travelled distance, since the emissions from the waste treatment alternative (landfill) are higher by one order of magnitude. Both $N$ and, to a lesser extent, the travelled distance influence the increase in the GHG emissions that would occur when preferring the use of hand driers in the current energy scenario $(32 \%$ of electric energy from renewable sources, Case 2) to the use of paper towels that are sent to incineration after their use (Case 3).

In the ranges of distance and $N$ considered here, the use of paper towels is preferable in terms of GHG emissions, if waste towels are sent to incineration (Fig. 2(c)). However, the impact of the transportation of new paper towels and of the production of hand driers and paper towels may influence such results. By comparing the two worst-case scenarios (Cases 2 and 4), the avoided GHG emissions when choosing hand driers instead of paper towels (Fig. 2(d)) are similar to those obtained when comparing the best-case scenario for handdrier use (Case 1) with Case 4 (Fig. 2(b)). Even in this case, the increase in GHG emissions when choosing waste landfilling is insensitive to the travelled distance. This confirms the dominant role of landfilling in GHG emissions. The convenience of choosing hand driers generally increases with $N$ also from the environmental point of view. The comparison between Cases 2 and 3 is the only exception: if a medium-low share of renewable energy is used, the environmental impacts will depend mainly on the operation of hand driers, and the impacts from the transportation of waste towels will be secondary. However, other unquantified elements may lead to different results, e.g. the GHG emissions related to the production processes of both paper towels and hand driers and the transportation of paper towels and hand driers from the supplier to the final user. By assuming similar contributions from the transportation of the two products, the production process of paper towels and hand driers may modify the results obtained. Based on a recent study [4], the environmental 

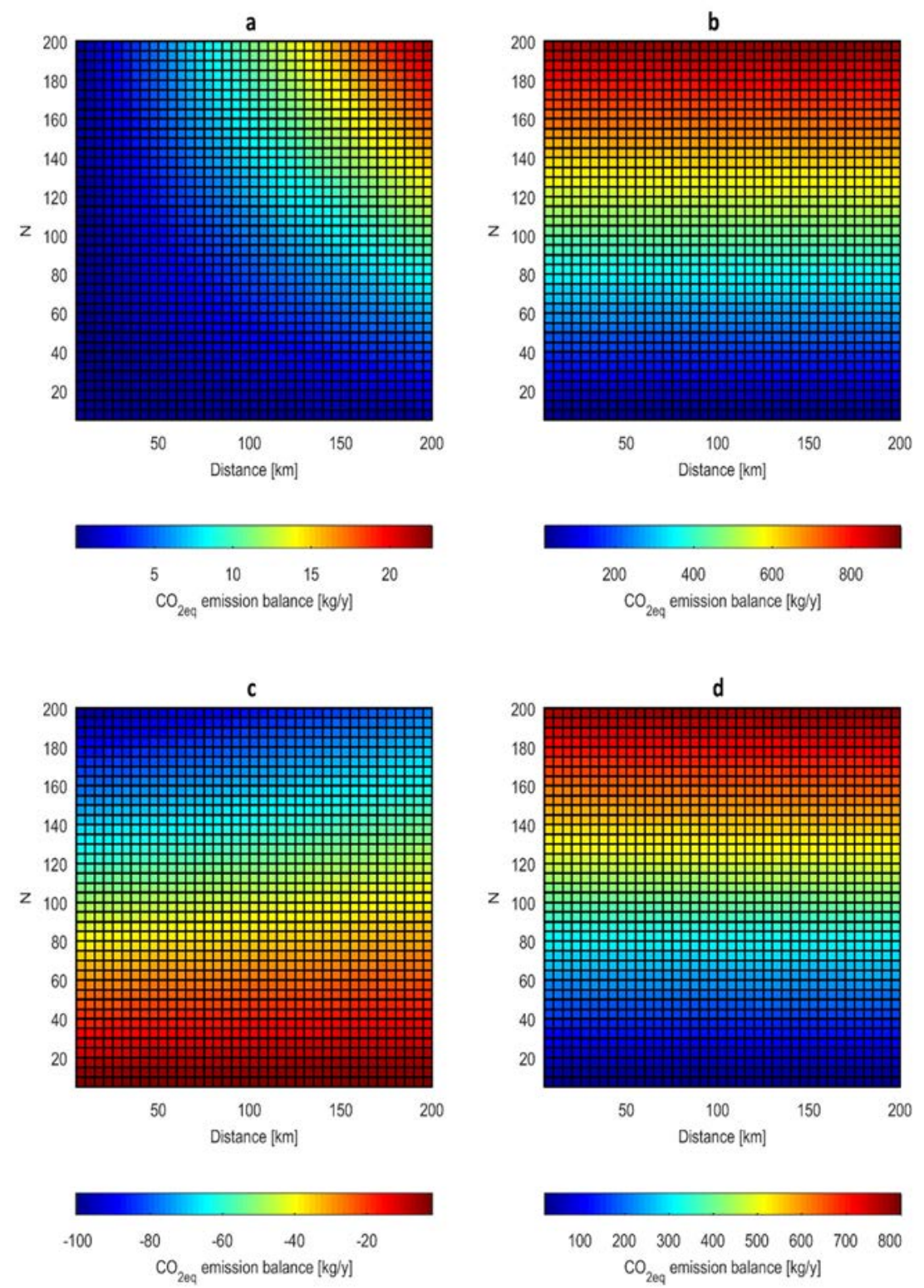

Figure 2: Differences in the $\mathrm{CO}_{2 \text { eq }}$ emissions between (a) Cases 3 and 1; (b) Cases 4 and 1; (c) Cases 3 and 2; and (d) Cases 4 and 2, as a function of the number of daily usages of a restroom and of the distance travelled by the HDVs transporting waste towels to the waste management option; the results refer to the most probable values estimated by the Monte Carlo simulation. 
impacts of hand driers are mainly related to their operation (i.e. to their energy consumption) if medium-low renewable energy is used, but GHG emissions from the manufacturing process are only slightly lower than the emissions expected from hand-drier operation. This might affect the results of the comparison between Cases 1 (100\% renewable energy) and 3 (incineration), and move the convenience towards the use of paper towels in terms of GHG emissions. However, the research carried out by [7] indicates that the GHG emissions from hand-drier manufacturing are about only $11 \%$ the emissions from hand-drier operation by one order of magnitude. Thus, as emerged in a previous paper [18], LCA results cannot be generalised and require a precise definition of the context and the used data.

\section{CONCLUSIONS}

This paper presented a methodology to evaluate the best option between two alternatives entailing costs and environmental impacts. In this paper, airblade-type hand driers and paper towels were evaluated from the economic and environmental points of view, by identifying a criterion for assessing the economic convenience of one or the other alternative and by estimating the GHG emissions from the two. In terms of carbon footprint, the use of airbladetype hand driers would be preferable to paper towels if electric energy were produced by $100 \%$ renewable sources, independently of the waste treatment alternative. In such cases, the use of a hand drier would allow saving up to $23 \mathrm{~kg} / \mathrm{y}$ and $925 \mathrm{~kg} / \mathrm{y}$ of $\mathrm{CO}_{2 \mathrm{eq}}$ when considering incineration and landfilling, respectively. The use of an airblade-type hand drier would be preferable to paper towels if landfilling were the waste treatment alternative, even when a medium-low share of electric energy from renewable sources is available. In this case, emission savings up to $824 \mathrm{~kg} / \mathrm{y}$ could be achieved, with an $89 \%$ reduction in $\mathrm{CO}_{2 \text { eq }}$ emissions. A similar comparative scenario is considered by the LCA procedure adopted in Montalbo et al. [7]: in this case, an airblade-type hand drier would allow for a $98 \%$ reduction in GHG emissions compared to paper towels. No clear conclusions can be made when the grid mix has a medium-low share of electric energy and waste incineration is available, since information on the travelled distance for product supply and on the manufacturing processes of hand driers and paper towels would be necessary to complete the comparisons. On the other hand, the economic analysis clearly showed that the convenience of using airblade-type hand driers increases with the number of daily usages of restrooms.

When uncertainties are too high to determine the environmental impacts, economic aspects would play a greater role in determining the best option between paper towels and airblade-type hand driers. Specifically, airblade-type hand driers are preferable in restrooms characterised by a medium-high number of daily usages. On an annual basis, considering the assumptions made in Section 2.1, a restroom equipped with an airblade-type hand drier would cost $58 \%$ and $77 \%$ less than a restroom equipped with waste towels, respectively for 90 and 200 mean daily usages. Coupling economic and environmental aspects is a useful strategy to fully assess the convenience of choosing one option rather than another, without limiting the decision to only one aspect. Although the presented methodology considers the great uncertainties that characterise such an analysis, this procedure should account for additional factors that may influence the results, e.g. information on the production processes and on the logistics. Based on the available information, this study showed the potential benefits of replacing paper towels with airblade-type hand driers (in spite of their probable lower level of achievable hygiene) if an economic criterion and the different possibilities of grid mix and waste treatment are properly considered. The proposed methodology is replicable not only in Italian contexts; however, it is clear that the public adoption of hand-dryers in low-medium income countries is made difficult by factors like purchasing power and available expertise for devices maintenance. 


\section{REFERENCES}

[1] Gul, M.S. \& Patidar, S., Understanding the energy consumption and occupancy of a multi-purpose academic building. Energy and Buildings, 87, pp. 155-165, 2015. DOI: 10.1016/j.enbuild.2014.11.027.

[2] Asimakopoulos, D.A. et al., Modelling the energy demand projection of the building sector in Greece in the 21st century. Energy and Buildings, 49, pp. 488-498, 2012. DOI: 10.1016/j.enbuild.2012.02.043.

[3] Jiang, P., Chen, Y., Dong, W. \& Huang, B., Promoting low carbon sustainability through benchmarking the energy performance in public buildings in China. Urban Climate, 10, 92-104, 2014. DOI: 10.1016/j.uclim.2014.10.004.

[4] Joseph, T., Baah, K., Jahanfar, A. \& Dubey, B., A comparative life cycle assessment of conventional hand dryer and roll paper towel as hand drying methods. Science of the Total Environment, 515-516, pp. 109-117, 2015. DOI: 10.1016/j.scitotenv.2015.01.112.

[5] Matthews, J.A. \& Newsome, S.W.B., Hot air electric hand driers compared with paper towels for potential spread of airborne bacteria. Journal of Hospital Infection, 9(1), pp. 85-88, 1987. DOI: 10.1016/0195-6701(87)90101-0.

[6] Best, E.L., Parnell, P. \& Wilcox, M.H., Microbiological comparison of hand-drying methods: the potential for contamination of the environment, user, and bystander. Journal of Hospital Infection, 88(4), pp. 199-206, 2014. DOI: 10.1016/j.jhin.2014.08.002.

[7] Montalbo, T., Gregory, J. \& Kirchain, R., Life Cycle Assessment of Hand Drying Systems. Technical Report. Materials Systems Laboratory: MIT, USA, 2011.

[8] RUS-University Network for Sustainable Development, Online. https://sites.google.com/unive.it/rus/. Accessed on: 3 May 2018.

[9] Schreider, Yu.A., Buslenko, N.P., Golenko, D.I., Sobol', I.M. \& Sragovich, V.G., (eds), The Monte Carlo Method. Pergamon Press: Oxford, pp. 1-90, 1966.

[10] European Environment Agency, EMEP/EEA air pollutant emission inventory guidebook 2016-Last Update June 2017. Technical report, 2017.

[11] Understanding Global Warming Potentials, Greenhouse Gas Emissions; U.S. Environmental Protection Agency, Climate Change Division, Online. www.epa.gov/ghgemissions/understanding-global-warming-potentials. Accessed on: 4 May 2018.

[12] Ciuta, S. et al., Role of feedstock transport in the balance of primary PM emissions in two case-studies: RMSW incineration vs. sintering plant. UPB Scientific Bulletin Series D, 74, pp. 211-218, 2012.

[13] European Union, Commission Regulation (EU) No 582/2011 of 25 May 2011 implementing and amending Regulation (EC) No 595/2009 of the European Parliament and of the Council with respect to emissions from heavy duty vehicles (Euro VI) and amending Annexes I and III to Directive 2007/46/EC of the European Parliament and of the Council. Official Journal of the European Union L167/1, 2011.

[14] Lee, J., Kang, S., Kim, S., Kim, K.-H. \& Jeon, E.-C., Development of municipal solid waste classification in Korea based on fossil carbon fraction. Journal of the Air \& Waste Management Association, 65(10), pp. 1256-1260, 2015. DOI: 10.1080/10962247.2015.1079563.

[15] Levis, J.W. \& Barlaz, M.A., Is biodegradability a desirable attribute for discarded solid waste? Perspectives from a National Landfill Greenhouse gas inventory model. Environmental Science \& Technology, 45(13), pp. 5470-5476, 2011. DOI: 10.1021/es200721s. 
[16] Wang, B., Nges, I.A., Nistor, M. \& Liu, J., Determination of methane yield of cellulose using different experimental setups. Water Science and Technology, 70(4), pp. 599604, 2014. DOI: 10.2166/wst.2014.275.

[17] Istituto Superiore per la Protezione e la Ricerca Amb. (ISPRA), Emission factors of $\mathrm{CO} 2$ and other greenhouse gasses in the electricity sector (in Italian), Technical report, 2017.

[18] Schiavon, M., Ragazzi, M., Rada, E.C. \& Merler, G., Proposal for the correct management of the Life Cycle Assessment results from integrated municipal solid waste treatment. WIT Transactions on Ecology and the Environment 180, pp. 163173, 2014. 